\title{
Synthetic Control of Manganese Birnessite: Impact of Crystallite Size on Li, Na, and Mg based Electrochemistry
}

Jiefu Yin ${ }^{\mathrm{a}}$, Esther S. Takeuchi, ${ }^{\mathrm{a}, \mathrm{b}, \mathrm{c} *}$ Kenneth J. Takeuchi, ${ }^{\mathrm{a}, \mathrm{b} *}$ Amy C. Marschilok ${ }^{\mathrm{a}, \mathrm{b}, \mathrm{c} *}$

a. Department of Chemistry, Stony Brook University, Stony Brook, NY 11794

b. Department of Materials Science and Engineering, Stony Brook University, Stony Brook, NY 11794

c. Energy Sciences Directorate, Brookhaven National Laboratory, Upton, NY 11973

* Corresponding Authors: $\quad$ (EST) esther.takeuchi@stonybrook.edu,

kenneth.takeuchi.1@stonybrook.edu. (ACM) amy.marschilok@stonybrook.edu

\begin{abstract}
The synthesis and characterization of $\mathrm{Mg}$-birnessite $\left(\mathrm{Mg}_{\mathrm{x}} \mathrm{MnO}_{2}\right)$ with different crystallite sizes, prepared though low temperature precipitation and ion exchange was demonstrated. The influence of crystallite size on electrochemical performance of $\mathrm{Mg}$-birnessite was studied for the first time, where material with smaller crystallite size was demonstrated to have enhanced capacity and rate capability in $\mathrm{Li}$ ion, $\mathrm{Na}$ ion, and $\mathrm{Mg}$ ion based electrolytes. Cation diffusion using GITT type testing demonstrated the ion diffusion coefficient of $\mathrm{Mg}^{2+}$ was $\sim 10 \mathrm{X}$ lower compared with $\mathrm{Li}^{+}$and $\mathrm{Na}^{+}$. This work illustrates that tuning of inorganic materials properties can lead to significant enhancement of electrochemical performance in lithium, sodium as well as magnesium based batteries for materials such as Mg-birnessite and provides a deliberate approach to improve electrochemical performance.
\end{abstract}


Keywords magnesium birnessite; manganese oxide; sol gel; lithium ion battery; sodium ion battery; magnesium ion battery

\section{Introduction}

Rechargeable Li-ion batteries (LIB) are one of the most commercially successful energy storage devices whose use has seen significant expansion over the past two decades. The research and subsequent commercialization of generations of $\mathrm{Li}$-ion batteries have promoted the development of new electronic devices, medical devices and electric vehicles. Despite the success of Li-ion batteries, several factors may impede even broader implementation, including safety concerns, high cost, and the natural scarcity of Li. Recently, significant effort has been devoted to the research \& development of alternatives to lithium battery systems, including sodium and magnesium based systems.

Sodium based batteries are considered a promising alternative to LIB.(1, 2) Sodium is among the most abundant elements on earth with a more uniform distribution than lithium. Beyond the low cost and natural abundance, $\mathrm{Na}^{+}$typically has lower de-solvation energy than $\mathrm{Li}^{+}$, which is benefit for the ion diffusion kinetics. In addition to sodium ion batteries, magnesium ion batteries are also promising battery systems. Magnesium based batteries are another promising alternative to LIB due as magnesium is abundant in the earth's crust, and the non-dendritic deposition at the magnesium surface makes $\mathrm{Mg}$ a safer anode alternative to Li.(3-5) However, the development of magnesium based batteries has been hampered by several challenges, including the slow kinetics associated with $\mathrm{Mg}^{2+}$ (de)insertion into a host lattice. The slow kinetics have been attributed to the high polarization and charge density of $\mathrm{Mg}^{2+} .(6,7)$ Introducing small amounts of strong dipole molecules can facilitate $\mathrm{Mg}^{2+}$ diffusion and insertion 
kinetics, which has been termed the "shielding effect".(8) It has been postulated that water is more effective at solvating small, highly charged ions than organic molecules of the electrolyte, as the water molecules hinder the ion pairing of $\mathrm{Mg}^{2+}$ with counter anions, thus reducing the electrostatic interaction between $\mathrm{Mg}^{2+}$ and the host lattice.(9) Another possible advantage of water in the electrolyte is that the de-solvation energy of $\mathrm{Mg}^{2+}$ is lower in aqueous environment, in other words, the charge transfer process is facilitated by water molecules.(9) The shielding effect was first demonstrated in $\mathrm{V}_{2} \mathrm{O}_{5},(8,10)$ and was recently reported for amorphous $\mathrm{MnO}_{2}$ nanowires.(11) Additionally, a recent report described the structural rearrangement of pristine birnessite (no interlayer cations) upon hydrated $\mathrm{Mg}^{2+}$ insertion.(12) A reversible phase transition during discharge/charge process was observed while the (002) interlayer water maintained its arrangement, further stabilizing the host lattice. The water molecules in electrolyte facilitated $\mathrm{Mg}^{2+}$ kinetics through shielding and by reducing the interfacial resistance.(12)

Manganese oxide materials are desirable cathode materials due to their low cost and environmentally benign character. Specifically, 2-D layered birnessite $\left(\mathrm{R}_{\mathrm{y}} \mathrm{MnO}_{2} \cdot \mathrm{xH}_{2} \mathrm{O}, \mathrm{R}=\right.$ monovalent or divalent metal ions) materials are conceptually appealing because of their excellent ion-exchange properties, $(13,14)$ and can be prepared via aqueous $(15,16)$ and nonaqueous(15) sol gel synthesis routes. Edge-sharing $\mathrm{MnO}_{6}$ octahedra constitute the $\mathrm{MnO}_{2}$ layers where the interlayer spacing of $7 \AA$ is occupied by metal ions and water molecules.(17) Previous electrochemical studies demonstrated the insertion/de-insertion capability of birnessite in $\mathrm{Li}^{+},(18-21) \mathrm{Na}^{+},(22,23) \mathrm{Mg}^{2+}$ electrolytes. $(12,24)$ Our previous studies revealed strong correlations between crystallite size and electrochemical performance with notable improvements in delivered capacity by smaller crystallite size materials for both silver hollandite $\left(\mathrm{Ag}_{\mathrm{x}} \mathrm{Mn}_{8} \mathrm{O}_{16}\right)(25)$ and magnetite $\left(\mathrm{Fe}_{3} \mathrm{O}_{4}\right)$. (26) Conductivity can be also enhanced on smaller 
crystallite size materials by reduced bandgap, originating from higher numbers of surface defects.(26) Under intermittent pulsatile discharge, magnetite achieved a $\sim 30 \%$ capacity enhancement with a 35\% decrease in crystallite size. Additionally, smaller crystallites were demonstrated to have more evenly distributed and uniform discharge by Transmission X-ray Microscopy combined with X-ray absorption near edge spectroscopy (TXM-XANES). (27) The smaller silver hollandite crystallites also showed better performance at different discharge rates where the discharge capacity was $40 \%$ higher than larger crystallites from $1 \mathrm{C}$ to $8 \mathrm{C}$ rates.(25) However, the crystallite size effect in rechargeable sodium and magnesium batteries has not yet been reported. To our knowledge, this is the first investigation of the crystallite size effect for reversible sodium and magnesium electrochemistry.

Herein, we designed a study of a Mg cation containing birnessite based with different crystallite sizes synthesized through a room temperature precipitation and ion exchange reaction, and characterized to determine structure and magnesium content. Electrochemical behavior was determined using cyclic voltammetry and galvanostatic testing in lithium ion, sodium ion and magnesium ion based electrolytes, where the influence of crystallite size on electrochemical activity of Mg-birnessite was evaluated. Additionally, the role of electrolyte solvent and of added water in the electrolyte in conjunction with crystallite size was studied for the magnesium based system. The cation diffusion coefficient in different electrolyte system was evaluated via Galvanostatic intermittent titration technique (GITT). The data affirm the impact of material crystallite size on the resultant electrochemistry.

\section{Experimental section}

\subsection{Synthesis}


Mg-birnessite was synthesized using modifications to a previously reported method.(14) Briefly, sodium hydroxide aqueous solution, manganese (II) nitrate, and sodium persulfate powder were used as the starting materials for the reaction. The as-synthesized Na-birnessite $\left(\mathrm{Na}_{\mathrm{x}} \mathrm{MnO}_{2}\right)(\sim 0.7 \mathrm{~g})$ was used to prepare $\mathrm{Mg}$-birnessite $\left(\mathrm{Mg}_{\mathrm{y}} \mathrm{MnO}_{2}\right)$ through ion-exchange with 1 $\mathrm{M}$ aqueous magnesium nitrate for $24 \mathrm{~h}$. The sample with smaller crystallite size was denoted as MgB-1, and the larger crystallite size sample as MgB-2. The concentrations of the reactants were adjusted to yield products of different crystallite size: $0.056 \mathrm{M} \mathrm{Mn}^{2+}, 1 \mathrm{M} \mathrm{NaOH}, 0.138 \mathrm{M}$ $\mathrm{Na}_{2} \mathrm{~S}_{2} \mathrm{O}_{8}$ for MgB-1; $0.222 \mathrm{M} \mathrm{Mn}^{2+}, 4 \mathrm{M} \mathrm{NaOH}, 0.55 \mathrm{M} \mathrm{Na}_{2} \mathrm{~S}_{2} \mathrm{O}_{8}$ for MgB-2.

\subsection{Characterization}

X-ray powder diffraction (XRD) data was collected using a Rigaku Smart Lab diffractometer with $\mathrm{Cu}-\mathrm{K} \alpha$ radiation. The crystallite size was calculated by applying the Scherrer equation(28) to the FWHM of the (001) peak. An instrumental broadening correction was applied using a $\mathrm{LaB}_{6}$ standard. Simultaneous thermogravimetric analysis/differential scanning calorimetry (TGA/DSC) data was measured using a TA instrument SDT Q600. Material composition was determined through inductively coupled plasma-optical emission spectroscopy (ICP-OES) using a Thermofisher iCAP 6300 series instrument. SEM images were collected with

a JEOL JSM-6010PLUS in secondary electron imaging mode. $\mathrm{N}_{2}$ adsorption-desorption measurements were performed using a Quantachrome Nova 4200e instrument and a multipoint BET (Brunauer, Emmett, and Teller) method was used for calculating the surface area.

\subsection{Electrochemical testing}

Electrodes were prepared using Mg-birnessite, carbon and PVDF binder coated onto aluminum foil. Cyclic voltammetry (CV) of the Mg-birnessite samples was conducted inside an argon-filled glovebox using a three electrode system: the working electrode contained Mg- 
birnessite, and the counter and reference electrodes were lithium metal. A scan rate of $0.5 \mathrm{mV} / \mathrm{s}$ over a voltage window of 2.0 to $4.1 \mathrm{~V}$ was used. The electrolyte was $1.0 \mathrm{M} \mathrm{LiPF}_{6}$ in ethylene carbonate (EC)/dimethyl carbonate (DMC) (v/v 30/70). Galvanostatic cycling data used cointype cells with lithium anodes tested between voltage limits of $2.0 \mathrm{~V}$ and $3.8 \mathrm{~V}$ at rates of $0.2 \mathrm{C}$, 1.0 C, and 2.0 C $(1 \mathrm{C}=170 \mathrm{~mA} / \mathrm{g})$.

Galvanostatic cycling tests in $\mathrm{Na}^{+}$electrolyte were conducted in $1.0 \mathrm{M} \mathrm{NaPF}_{6}$ in ethylene carbonate (EC)/diethyl carbonate (DEC) (v/v 50/50) using coin type cells, sodium metal was used as anode. The voltage window was $1.6 \mathrm{~V}$ to $3.3 \mathrm{~V}$, at rates of $0.1 \mathrm{C}, 0.5 \mathrm{C}$, and $1.0 \mathrm{C}$.

For $\mathrm{CV}$ testing in $\mathrm{Mg}^{2+}$ electrolyte, the working electrode contained Mg-birnessite, a carbon counter electrode was used along with a silver/silver nitrate reference electrode. The electrolyte was $0.4 \mathrm{M}$ magnesium (II) bis-(trifluoromethane sulfonyl) imide $\left(\mathrm{Mg}(\mathrm{TFSI})_{2}\right) / 0.5 \mathrm{M}$ dipropylene glycol dimethyl ether (dipro-glyme) in acetonitrile. A scan rate of $0.5 \mathrm{mV} / \mathrm{s}$ was used with a voltage window of 1.2 to $-0.8 \mathrm{~V}$. The water content in the electrolyte was adjusted by adding water and measuring the content using a Karl Fischer Titrator. Galvanostatic cycling data in magnesium electrolyte was tested using voltage limits of -0.8 and $0.9 \mathrm{~V}$. Rates of $0.2 \mathrm{C}, 0.5 \mathrm{C}$, 1.0 C, and 2.0 $\mathrm{C}$ were used for charge and discharge.

Galvanostatic intermittent titration technique (GITT) measurement were conducted at 0.2 $\mathrm{C}$ in $\mathrm{Li}^{+}$and $\mathrm{Mg}^{2+}$ electrolytes (same as galvanostatic cylcling tests), at $0.1 \mathrm{C}^{\text {in }} \mathrm{Na}^{+}$electrolyte (same as galvanostatic cycling tests) by applying a galvanostatic step of $10 \mathrm{~min}$ for $\mathrm{Li}^{+}$and $\mathrm{Mg}^{2+}$ test and $20 \mathrm{~min}$ for $\mathrm{Na}^{+}$test, and a relaxation time of $4 \mathrm{~h}$ for the $\mathrm{Li}^{+}$test, $8 \mathrm{~h}$ for the $\mathrm{Mg}^{2+}$ test, $2 \mathrm{~h}$ for the $\mathrm{Na}^{+}$test.

\section{Results and discussion}




\subsection{Synthesis and characterization}

The as-synthesized Mg-birnessite materials were characterized by X-ray powder diffraction (XRD). The XRD patterns shown in Figure 1a matched closely with the monoclinic phase (space group C 2/m) Mg-birnessite (ICSD 68917). Mg-birnessite has a layered structure comprised of edge-shared $\mathrm{MnO}_{6}$ octahedra with $\mathrm{Mg}^{2+}$ ions and water molecules between the layers, as shown in Figure 1b. Specifically, Mg-birnessite is a type B birnessite with the following lattice parameters: $a=5.050 \AA, b=2.846 \AA, c=7.054 \AA, \beta=96.63^{\circ}$,(29) while Nabirnessite is a type A birnessite with the following lattice parameters: $\mathrm{a}=5.174 \AA$ A, $\mathrm{b}=2.850 \AA$, c $=7.336 \AA, \beta=103.18^{\circ},(30)$ consistent with the higher charge density of $\mathrm{Mg}^{2+}(0.72 \AA)$ relative to $\mathrm{Na}^{+}(1.02 \AA) .(31,32)$ As a type B birnessite, $\mathrm{Mg}^{2+}$ is located between the interlayer hydrates and the $\mathrm{MnO}_{6}$ layer in $\mathrm{Mg}$-birnessite, while the cations share the same layer with the water molecule in type A birnessites such as Na-birnessite.(13) In Mg-birnessite, $\mathrm{Mg}^{2+}$ coordinates octahedrally with three oxygen atoms from the $\mathrm{MnO}_{6}$ layer and three oxygen atoms from water molecules, where the $\mathrm{Mg}$-O bond lengths range from $1.879 \AA$ to $2.387 \AA$, as shown in Figure 1b.(29) The $\mathrm{MnO}_{6}$ octahedron has $4 \mathrm{Mn}-\mathrm{O}$ bond lengths of $1.926 \AA$ and $2 \mathrm{Mn}-\mathrm{O}$ bond lengths of $1.952 \AA$, reflecting that $\mathrm{Mn}^{3+}$ has a high spin $\mathrm{d}^{4}$ electron configuration, where the Jahn-Teller effect can be observed in the $\mathrm{MnO}_{6}$ units. Two strong diffraction peaks at $12.3^{\circ}(001)$ and $24.8^{\circ}$ (002), Figure 1a, indicating highly ordered layers along the c axis, while the remaining peaks were lower intensity and broad, suggesting that the as-synthesized samples were nanocrystalline. The (001) peak was used to determine the interlayer spacing of $7.2 \AA$ and the crystallite sizes of $9 \mathrm{~nm}(\mathbf{M g B}-1)$ and $23 \mathrm{~nm}(\mathbf{M g B}-2)$.

The chemical composition of as-synthesized Mg-birnessite samples was determined through a combination of TGA/DSC and ICP-OES analysis. A typical TGA/DSC curve of MgB- 
1 is shown in Figure 2. Due to its high charge density and hydration enthalpy ( 2000 $\mathrm{kJ} / \mathrm{mol}$ ),(17) $\mathrm{Mg}^{2+}$ can strongly retain the interlayer hydrates, which results in a broader temperature range for $\mathrm{Mg}$-birnessite water loss from room temperature to $250^{\circ} \mathrm{C}$, while the water loss process in Na-birnessite ends at $150^{\circ} \mathrm{C}$. Based on the TGA results, the water comprised $14.8 \%$ of the total sample mass, where the surface water amount was estimated as $2.8 \%$ based on the mass loss at the temperature corresponding to the strong first DSC peak below $100^{\circ} \mathrm{C}$. The $\mathrm{Mg}$ and $\mathrm{Na}$ content of the as-synthesized Mg-birnessite samples was determined by ICP-OES. Thus, from the TGA and ICP-OES results, the chemical formula of $\mathrm{Mg}_{0.15} \mathrm{Na}_{0.02} \mathrm{MnO}_{2} \cdot 0.7 \mathrm{H}_{2} \mathrm{O}$ was assigned to MgB-1, $\mathrm{Mg}_{0.14} \mathrm{Na}_{0.04} \mathrm{MnO}_{2} \cdot 0.7 \mathrm{H}_{2} \mathrm{O}$ was assigned to MgB-2. Scanning electron microscopy images of Mg-birnessite samples showed a morphology consisting of agglomerates of sub-micron sized particles, with granular morphology, with no significant morphology differences between the two samples, shown in Figure 3. The BET surface area for MgB-1 is 66 $\mathrm{m}^{2} / \mathrm{g}$, which is slightly larger than the value for MgB-2, $58 \mathrm{~m}^{2} / \mathrm{g}$.

\subsection{Lithium based electrochemistry}

The electrochemical properties of the as-synthesized Mg-birnessite samples were studied in $\mathrm{Li}^{+}$containing electrolyte. The cyclic voltammetry of the $9 \mathrm{~nm} \mathrm{MgB-1}$ showed a major redox couple at $\sim 2.60 \mathrm{~V} / 3.30 \mathrm{~V}$, which can be assigned to the $\mathrm{Mn}^{4+} / \mathrm{Mn}^{3+}$ couple, Figure 4a.(33) Similar to prior reports for K-birnessite, two shoulder peaks can be observed at around 3.00 and 3.80 V.(18, 34) MgB-2 with a $23 \mathrm{~nm}$ crystallite size showed $\sim 40 \%$ lower current on both cathodic and anodic peaks. The discharge/charge cycling performance of MgB-1 and MgB-2 was studied. MgB-1 delivered $197 \mathrm{mAh} / \mathrm{g}$ initial capacity at $0.2 \mathrm{C}\left(1.16 \mathrm{Li}^{+}\right.$insertion $), 128$ $\mathrm{mAh} / \mathrm{g}$ at $1.0 \mathrm{C}\left(0.75 \mathrm{Li}^{+}\right.$insertion $)$, and $98 \mathrm{mAh} / \mathrm{g}$ at $2.0 \mathrm{C}\left(0.58 \mathrm{Li}^{+}\right.$insertion $)$, while the values 
for MgB-2 are $154 \mathrm{mAh} / \mathrm{g}$ at $0.2 \mathrm{C}\left(0.91 \mathrm{Li}^{+}\right.$insertion $), 97 \mathrm{mAh} / \mathrm{g}$ at $1.0 \mathrm{C}\left(0.57 \mathrm{Li}^{+}\right.$insertion), and $63 \mathrm{mAh} / \mathrm{g}$ at $2.0 \mathrm{C}\left(0.37 \mathrm{Li}^{+}\right.$insertion $)$. Both the $\mathrm{CV}$ results as well as the galvanostatic discharge results affirm the improved delivered capacity from MgB-1, the smaller crystallite sized material.

The AC impedance results are shown in Figure 4d, the typical shape of the curves is a semi-circle in high frequency range, which corresponds to the electrolyte resistance and charge transfer resistance, and a straight line with slope in low frequency range, which is the characteristic shape for ion diffusion in a solid. The initial impedance from as-prepared cells was similar between MgB-1 and MgB-2. The impedance of both materials increased after the cycling test. The smaller crystallite size MgB-1 with larger surface area and shorter ion diffusion pathways displays $\sim 25 \%$ improvement in discharge capacity at each rate, and lower impedance compared to the larger sized material MgB-2 in lithium ion based electrolyte.

\subsection{Sodium based electrochemistry}

The electrochemical properties of the as-synthesized Mg-birnessite samples were studied in $\mathrm{Na}^{+}$containing electrolyte. The discharge/charge cycling performance of MgB-1 and MgB-2 is shown in Figure 5 where MgB-1 delivered $165 \mathrm{mAh} / \mathrm{g}$ initial discharge capacity at $0.1 \mathrm{C}$, corresponding to $0.97 \mathrm{Na}^{+}$insertion, the value of MgB-2 was $142 \mathrm{mAh} / \mathrm{g}\left(0.84 \mathrm{Na}^{+}\right.$insertion $)$, Figure 5b. MgB-1 showed $\sim 20 \%$ higher capacity than MgB-2 at 0.2 C, $\sim 25 \%$ higher capacity at $0.5 \mathrm{C}$, and $\sim 18 \%$ higher capacity at $1.0 \mathrm{C}$. Notably, the smaller crystallite size material samples provided improved electrochemistry in a sodium based system.

Figure 5c compares the impedance data of MgB-1 and MgB-2 before and after cycling. The higher initial impedance of as-prepared cells has been assigned to charge transfer resistance.(23) Interestingly, the impedance became smaller after cycling, likely to the removal 
of a passivation layer. MgB-1 showed lower impedance at both stages than MgB-2, which agrees with the better performance of MgB-1 in the cycling test. The results indicate that $\mathrm{Na}^{+}$insertion can be facilitated by the smaller crystallite size of the MgB-1 material, especially at high rates. The cycling performance and rate capability demonstrated that Mg-birnessite may be a promising cathode material for sodium ion batteries.

\subsection{Magnesium based electrochemistry}

The electrolyte used for the magnesium ion battery test was $0.4 \mathrm{M} \mathrm{Mg}(\mathrm{TFSI})_{2}$ in acetonitrile with addition of $2.4 \mathrm{M}$ water and $0.5 \mathrm{M}$ dipropylene glycol dimethyl ether (diproglyme). It has been demonstrated that water facilitate the solvation of $\mathrm{Mg}^{2+}$ and reduce the repulsion from cathode lattice. $(11,12)$ Glycol ether based compounds have been used as additives or solvents in organic electrolyte systems.(35, 36) Their flexible backbone and polydentate properties can facilitate the solvation of $\mathrm{Mg}^{2+}$, yet long chain polyethers can also limit the mobility of $\mathrm{Mg}^{2+}$. Thus, we identified a novel solvent, dipropylene glycol dimethyl ether (dipro-glyme) with three oxygen donor atoms as an additive for the electrolyte with the motivation of facilitating $\mathrm{Mg}$ ion solvation with no negative impact on performance. The electrochemical performance of MgB-1 was studied by cyclic voltammetry in electrolytes using $\operatorname{Mg}(\mathrm{TFSI})_{2}$ in an acetonitrile electrolyte system with and without dipro-glyme, Figure 6. The $\mathrm{CV}$ conducted in anhydrous conditions demonstrated low peak currents, Figure 6a. These data indicate that the interlayer water alone is not sufficient for reversible electrochemistry. However, in the presence of added water at a molar ratio of $\mathrm{Mg}^{2+} /$ water $=1 / 6$, the cathodic and anodic peaks were clearly visible, Figure 6b. Notably, even though the water content was the same in both electrolyte solutions, the sample containing the ether based solvent showed higher peak 
currents than the sample in acetonitrile alone. The anodic peak in the electrolyte without diproglyme is significantly lower than in the electrolyte containing the dipro-glyme. It is clear that the addition of dipro-glyme assists the solvation of $\mathrm{Mg}^{2+}$ and facilitated de-insertion from the $\mathrm{Mg}$ birnessite structure.(35) This finding motivated a more detailed study of the water content in acetonitrile based electrolyte and electrolyte containing ether functionality.

After optimization of the magnesium electrolyte system, the crystallite size effect was studied. Figure 7 compares the $\mathrm{CV}$ curves between MgB-1 and MgB-2 in $0.4 \mathrm{M} \mathrm{Mg}(\mathrm{TFSI})_{2}$ / acetonitrile and 0.5 M dipro-glyme with water present, MgB-1 had higher peak current than MgB-2 on both cathodic and anodic peak, the reversibility was also enhanced by the smaller crystallite size of MgB-1. The current retention of the $2^{\text {nd }}$ cathodic peak of MgB-1 in $\mathrm{Mg}^{2+} /$ water $=1 / 6$ electrolyte was $91 \%$, yet the number for MgB-2 was $71 \%$. The CV results at a scan rate of $0.5 \mathrm{mV} \mathrm{s}^{-1}$ illustrated that the $\mathrm{Mg}^{2+}$ insertion/de-insertion kinetics are more limited by the larger crystallite. Galvanostatic cycling data was collected in $0.4 \mathrm{M} \mathrm{Mg}(\mathrm{TFSI})_{2} /$ acetonitrile and $0.5 \mathrm{M}$ dipro-glyme with $\mathrm{Mg}^{2+} /$ water $=1 / 6$ at rates of $0.2 \mathrm{C}, 0.5 \mathrm{C}, 1.0 \mathrm{C}$, and 2.0 $\mathrm{C}$ to evaluate the capacity and reversibility of Mg-birnessite samples, Figure 8. In the $1^{\text {st }}$ discharge curve of MgB-1, a plateau can be observed at $\sim 0.2-0 \mathrm{~V}$ versus $\mathrm{Ag}^{+} / \mathrm{Ag}$, corresponding to $\sim 3.1-2.9 \mathrm{~V}$ versus $\mathrm{Mg}^{2+} / \mathrm{Mg}$. The MgB-1 showed $1^{\text {st }}$ discharge capacity of 136 $\mathrm{mAh} / \mathrm{g}$ at $0.2 \mathrm{C}$, corresponding to $0.4 \mathrm{Mg}^{2+}$ insertion, while the initial capacity of MgB-2 was 80 $\mathrm{mAh} / \mathrm{g}$. The capacity in this sample increased over following cycles to $125 \mathrm{mAh} / \mathrm{g}$. The crystallite size effect can be clearly observed at $0.5 \mathrm{C}, \mathrm{MgB}-1$ has $\sim 60 \mathrm{mAh} / \mathrm{g}$ capacity, which is 25\% higher than MgB-2. At rate higher than 0.5C, the influence of crystallite size was not observed, as both material showed very low specific capacity. After cycling at $0.2 \mathrm{C}, 0.5,1.0 \mathrm{C}$, and $2.0 \mathrm{C}$, the cells were again tested at $0.2 \mathrm{C}$, where the $\mathbf{M g B}-1$ delivered $92 \mathrm{mAh} / \mathrm{g}$ capacity, 
30\% percent higher than MgB-2. These results provide the first evidence of a crystallite size effect in $\mathrm{Mg}^{2+}$ containing electrolyte, where the shorter diffusion pathway and higher surface area in smaller crystallite size material can improve the sluggish kinetics of $\mathrm{Mg}^{2+}$ diffusion, resulting in enhanced capacity and reversibility. Thus, targeting small crystallite size materials could be a general strategy in the design of cathode materials for MIB.

\subsection{Cation diffusion study}

To evaluate cation diffusion coefficients in different battery systems, galvanostatic intermittent titration technique (GITT) type tests were performed in $\mathrm{Li}^{+}, \mathrm{Na}^{+}$, and $\mathrm{Mg}^{2+}$ based electrolytes. The cells were discharged in galvanostatic mode at a constant current for a fixed time interval followed by an open-circuit rest for a period of time to allow the cell voltage to relax to its steady-state value (Es). Figure 9a-c show the GITT results in $\mathrm{Li}^{+}, \mathrm{Na}^{+}, \mathrm{Mg}^{2+}$ electrolyte, respectively. When the relationship between cell potential and $\mathrm{s}^{1 / 2}$ is a straight line, the diffusion coefficient can be calculated via the equation:(37)

$$
D_{\mathrm{Li}+}=\frac{4}{\pi \tau}\left(\frac{m_{B} V_{M}}{M_{B} S}\right)^{2}\left(\frac{\Delta E_{S}}{\Delta E_{\tau}}\right)^{2}
$$

Where $V_{M}$ is the molar volume of the compound, $M_{B}$ is the relative formula mass, and $S$ is the area between the electrolyte and the active material, $\Delta \mathrm{E}_{\mathrm{s}}$ and $\Delta \mathrm{E}_{\tau}$ are shown in $\mathbf{c}$ figure in each electrolyte. Figure 9d shows the calculated diffusion coefficient values $\left(\mathrm{D}_{+}\right)$of MgB-1 in the different electrolyte systems (MgB-2 has similar values). The $\mathrm{D}_{\mathrm{Li}}{ }^{+}$and $\mathrm{D}_{\mathrm{Na}}{ }^{+}$values were in the $\sim 10^{-11}-10^{-13} \mathrm{~cm}^{2} / \mathrm{s}$ range, and decreased with the depth of discharge (DOD). $\mathrm{D}_{\mathrm{Mg}}{ }^{+}$showed values of $\sim 10^{-12}-10^{-14} \mathrm{~cm}^{2} / \mathrm{s}$ range with a similar trend with decreasing values with discharge. The $\mathrm{Mg}^{2+}$ diffusion in Mg-birnessite material was $\sim 10$ times lower than $\mathrm{Li}^{+}$and $\mathrm{Na}^{+}$diffusion, 
the average values of the diffusion coefficients in different electrolyte are: $1.4 \times 10^{-11} \mathrm{~cm}^{2} / \mathrm{s}$ of $\mathrm{D}_{\mathrm{Li}}{ }^{+}, 1.1 \times 10^{-11} \mathrm{~cm}^{2} / \mathrm{s}$ of $\mathrm{D}_{\mathrm{Na}}^{+}, 1.2 \times 10^{-12} \mathrm{~cm}^{2} / \mathrm{s}$ of $\mathrm{D}_{\mathrm{Mg}}{ }^{+}$.

The ionic radius of $\mathrm{Li}^{+}$is $0.76 \AA$, while $\mathrm{Na}^{+}$is $1.02 \AA$, and $\mathrm{Mg}^{2+}$ is $0.72 \AA$. Considering the divalency of $\mathrm{Mg}^{2+}$, the ion surface charge density is in the order of $\mathrm{Mg}^{2+}>>\mathrm{Li}^{+}>\mathrm{Na}^{+}$.(2) More solvent molecules are needed to stabilize the strong charge density of $\mathrm{Mg}^{2+}$ during solvation process, resulting in a high de-solvation energy, which is directly related with ion diffusion kinetics in the solid.(2) Previous theoretical analysis of cation de-solvation energy in different solvent has demonstrated the de-solvation order of the three cations: $\mathrm{Mg}^{2+}$ has $490 \mathrm{~kJ} / \mathrm{mol} \mathrm{de}-$ solvation energy in acetonitrile, $\mathrm{Li}^{+}$has $211.3 \mathrm{~kJ} / \mathrm{mol}$ and $207.7 \mathrm{~kJ} / \mathrm{mol}$ de-solvation energy in EC and DEC, $\mathrm{Na}^{+}$has $151.9 \mathrm{~kJ} / \mathrm{mol}$ and $147.5 \mathrm{~kJ} / \mathrm{mol}$ de-solvation energy in EC and DEC.(38) Thus, the high de-solvation energy of $\mathrm{Mg}^{2+}$ limited the ion diffusion kinetics even when shielded by water molecules. The high charge density of $\mathrm{Mg}^{2+}$ also generates higher repulsion in the lattice structure of cathode material than $\mathrm{Li}^{+}$and $\mathrm{Na}^{+}$. The cation diffusion study shown here illustrated that the $\mathrm{Mg}^{2+}$ diffusion is still sluggish even when shielded by additive molecules, especially when it is compared with $\mathrm{Li}^{+}$and $\mathrm{Na}^{+}$diffusion.

\section{Summary}

Mg-birnessite with different crystallite sizes was successfully synthesized using a room temperature, aqueous-based strategy. The materials have a layered structure, with an interlayer spacing of 7.2 A as indicated by the [001] peak in the XRD pattern. The Mg-birnessite structure was selected to benefit from the "pillar effect" of $\mathrm{Mg}^{2+}$ in the structure and provide structural stability during electrochemical reduction and oxidation. The influence of crystallite size on electrochemical performance of Mg-birnessite was studied for the first time, where material with 
smaller crystallite size was demonstrated to have enhanced capacity and rate capability in Li ion, $\mathrm{Na}$ ion, and $\mathrm{Mg}$ ion based electrolytes. The cation diffusion study conducted using GITT method demonstrated the ion diffusion coefficient of $\mathrm{Mg}^{2+}$ was $\sim 10 \mathrm{X}$ lower compared with $\mathrm{Li}^{+}$ and $\mathrm{Na}^{+}$. Thus, the Mg-birnessite synthesized through a low temperature precipitation / ion exchange method allowing crystallite size control indicated beneficial effect on the electrochemistry material $\mathrm{Li}^{+}, \mathrm{Na}^{+}$, and $\mathrm{Mg}^{2+}$ based electrolyte system.

\section{Acknowledgement}

Support for the material synthesis, characterization, and the lithium and sodium electrochemistry was provided by the Center for Mesoscale Transport Properties, an Energy Frontier Research Center supported by the U.S. Department of Energy, Office of Science, Basic Energy Sciences, under award \#DE-SC0012673. Support for the magnesium electrochemistry described was provided by supported by the Department of Energy, Office of Electricity, administered through Sandia National Laboratories, Purchase Order \#1275961. The authors also acknowledge Brookhaven National Laboratory for the SmartLab X-ray Diffractometer. 


\section{Uncategorized References}

1. L. P. Wang, L. Yu, X. Wang, M. Srinivasan and Z. J. Xu, Journal of Materials Chemistry A, 3, 9353 (2015).

2. N. Yabuuchi, K. Kubota, M. Dahbi and S. Komaba, Chemical Reviews, 114, 11636 (2014).

3. M. Matsui, Journal of Power Sources, 196, 7048 (2011).

4. P. Saha, M. K. Datta, O. I. Velikokhatnyi, A. Manivannan, D. Alman and P. N. Kumta, Progress in Materials Science, 66, 1 (2014).

5. H. D. Yoo, I. Shterenberg, Y. Gofer, G. Gershinsky, N. Pour and D. Aurbach, Energy \& Environmental Science, 6, 2265 (2013).

6. E. Levi, A. Mitelman, D. Aurbach and M. Brunelli, Chemistry of Materials, 19, 5131 (2007).

7. M. M. Huie, D. C. Bock, E. S. Takeuchi, A. C. Marschilok and K. J. Takeuchi, Coordination Chemistry Reviews, 287, 15 (2015).

8. P. Novak and J. Desilvestro, Journal of the Electrochemical Society, 140, 140 (1993).

9. W. R. Fawcett and G. Liu, The Journal of Physical Chemistry, 96, 4231 (1992).

10. L. Yu and X. Zhang, Journal of Colloid and Interface Science, 278, 160 (2004).

11. J. Song, M. Noked, E. Gillette, J. Duay, G. Rubloff and S. B. Lee, Physical Chemistry Chemical Physics, 17, 5256 (2015). 
12. K. W. Nam, S. Kim, S. Lee, M. Salama, I. Shterenberg, Y. Gofer, J.-S. Kim, E. Yang, C. S. Park, J.-S. Kim, S.-S. Lee, W.-S. Chang, S.-G. Doo, Y. N. Jo, Y. Jung, D. Aurbach and J. W. Choi, Nano Letters, 15, 4071 (2015).

13. Q. Feng, H. Kanoh and K. Ooi, Journal of Materials Chemistry, 9, 319 (1999).

14. L. Athouël, F. Moser, R. Dugas, O. Crosnier, D. Bélanger and T. Brousse, The Journal of Physical Chemistry C, 112, 7270 (2008).

15. S. Ching, S. M. Hughes, T. P. Gray and E. J. Welch, Microporous and Mesoporous Materials, 76, 41 (2004).

16. S. Bach, M. Henry, N. Baffier and J. Livage, Journal of Solid State Chemistry, 88, 325 (1990).

17. E. A. Johnson and J. E. Post, American Mineralogist, 91, 609 (2006).

18. R. Renuka and S. Ramamurthy, Journal of Power Sources, 87, 144 (2000).

19. R. Ma, Y. Bando, L. Zhang and T. Sasaki, Advanced Materials, 16, 918 (2004).

20. D. Ahn, I. Yoo, Y.-M. Koo, N. Shin, J. Kim and T. J. Shin, Journal of Materials Chemistry, 21, 5282 (2011).

21. S. Bach, J. P. Pereira-Ramos, N. Baffier and R. Messina, Electrochimica Acta, 36, 1595 (1991).

22. S. H. Guo, H. J. Yu, Z. L. Jian, P. Liu, Y. B. Zhu, X. W. Guo, M. W. Chen, M. Ishida and H. S. Zhou, Chemsuschem, 7, 2115 (2014). 
23. K. W. Nam, S. Kim, E. Yang, Y. Jung, E. Levi, D. Aurbach and J. W. Choi, Chemistry of Materials, 27, 3721 (2015).

24. X. Q. Sun, V. Duffort, B. L. Mehdi, N. D. Browning and L. F. Nazar, Chemistry of Materials, 28, 534 (2016).

25. K. J. Takeuchi, S. Z. Yau, A. Subramanian, A. C. Marschilok and E. S. Takeuchi, Journal of The Electrochemical Society, 160, A3090 (2013).

26. S. Zhu, A. C. Marschilok, E. S. Takeuchi and K. J. Takeuchi, Electrochemical and SolidState Letters, 12, A91 (2009).

27. D. C. Bock, K. C. Kirshenbaum, J. Wang, W. Zhang, F. Wang, J. Wang, A. C. Marschilok, K. J. Takeuchi and E. S. Takeuchi, ACS Applied Materials \& Interfaces, 7, 13457 (2015).

28. P. Scherrer, Nachr. Ges. Wiss. Gottingen, 98 (1918).

29. J. E. Post and D. R. Veblen, American Mineralogist, 75, 477 (1990).

30. C. L. Lopano, P. J. Heaney, J. E. Post, J. Hanson and S. Komarneni, American Mineralogist 92, 380 (2007).

31. P. W. Atkins, Shriver \& Atkins' inorganic chemistry, Oxford University Press, Oxford; New York (2010).

32. D. C. Golden, C. C. Chen and J. B. Dixon, Clays and Clay Minerals, 35, 271 (1987). 
33. A. K. Thapa, B. Pandit, R. Thapa, T. Luitel, H. S. Paudel, G. Sumanasekera, M. K. Sunkara, N. Gunawardhana, T. Ishihara and M. Yoshio, Electrochimica Acta, 116, 188 (2014).

34. R. J. Chen and M. S. Whittingham, Journal of the Electrochemical Society, 144, L64 (1997).

35. N. N. Rajput, X. Qu, N. Sa, A. K. Burrell and K. A. Persson, Journal of the American Chemical Society, 137, 3411 (2015).

36. Y. Shao, T. Liu, G. Li, M. Gu, Z. Nie, M. Engelhard, J. Xiao, D. Lv, C. Wang, J.-G. Zhang and J. Liu, Scientific Reports, 3, 3130 (2013).

37. W. Weppner and R. A. Huggins, Journal of The Electrochemical Society, 124, 1569 (1977).

38. M. Okoshi, Y. Yamada, A. Yamada and H. Nakai, Journal of the Electrochemical Society, 160, A2160 (2013). 


\section{List of Figures.}

Figure 1. a) X-ray powder diffraction patterns of as-synthesized Mg-birnessite samples. b) Crystal structure of Mg-birnessite along b-axis. Pink octahedra with red balls are edge-shared $\mathrm{MnO}_{6}$ units; yellow balls are $\mathrm{Mg}^{2+}$; blue balls are water molecules. The coordination environments of $\mathrm{Mn}$ and $\mathrm{Mg}$ are also shown.

Figure 2. TGA/DSC curve of MgB-1. The pink shaded region indicates the water loss range.

Figure 3. Scanning electron micrographs (SEM) of MgB-1 at a) 5,000X and b) 20,000X, MgB-2 at c) $5,000 \mathrm{X}$ and d) $20,000 \mathrm{X}$.

Figure 4. a) Cyclic voltammetry test of MgB-1 (9 nm) and MgB-2 (23 nm) in $1 \mathrm{M} \mathrm{LiPF}_{6}$ in EC/DMC (30/70) at $0.5 \mathrm{mV} / \mathrm{s}$ scan rate. b) Discharge curve at different rate, using MgB-1 as example. c) Discharge capacity of Mg-birnessite samples. d) AC impedance spectroscopy results of MgB-1 and MgB-2 before and after galvanostatic cycling test.

Figure 5. Comparison of galvanostatic cycling results of MgB-1 (9 nm) and MgB-2 (23 nm) in $1 \mathrm{M}$ $\mathrm{NaPF}_{6}$ in EC/DEC (50/50): a) discharge curves of MgB-1 at different rate; b) Discharge capacity of each cycle.

Figure 6. a) Comparison of $2^{\text {nd }}$ cycle in electrolyte in anhydrous $0.4 \mathrm{M} \mathrm{Mg}(\mathrm{TFSI})_{2}$ / acetonitrile with or without dipro-glyme. b) Comparison of $2^{\text {nd }}$ cycle in electrolyte in acetonitrile with or without diproglyme with $\mathrm{Mg}^{2+} /$ water $=1 / 6$ molar ratio. 
Figure 7. Comparison of cyclic voltammetry results of MgB-1 (9 nm) and MgB-2 (23 nm) in $0.4 \mathrm{M}$ $\mathrm{Mg}(\mathrm{TFSI})_{2} /$ acetonitrile and $0.5 \mathrm{M}$ dipro-glyme with different water concentration and scan rate was 0.5 $\mathrm{mV} / \mathrm{s}$.

Figure 8. Galvanostatic cycling results of MgB-1 (9 nm) and MgB-2 (23 nm) in $0.4 \mathrm{M} \mathrm{Mg}(\mathrm{TFSI})_{2}$ / acetonitrile and $0.5 \mathrm{M}$ dipro-glyme with $\mathrm{Mg}^{2+} /$ water=1/6: a) discharge curve at different rate, using MgB1 as example; b) Discharge capacity of each cycle.

Figure 9. GITT results of MgB-1 and MgB-2 in a) $\mathrm{Li}^{+}$electrolyte, b) $\mathrm{Na}^{+}$electrolyte, c) $\mathrm{Mg}^{2+}$ electrolyte. d) Cation diffusion coefficients in MgB-1 in different electrolyte systems, calculated from GITT test. 

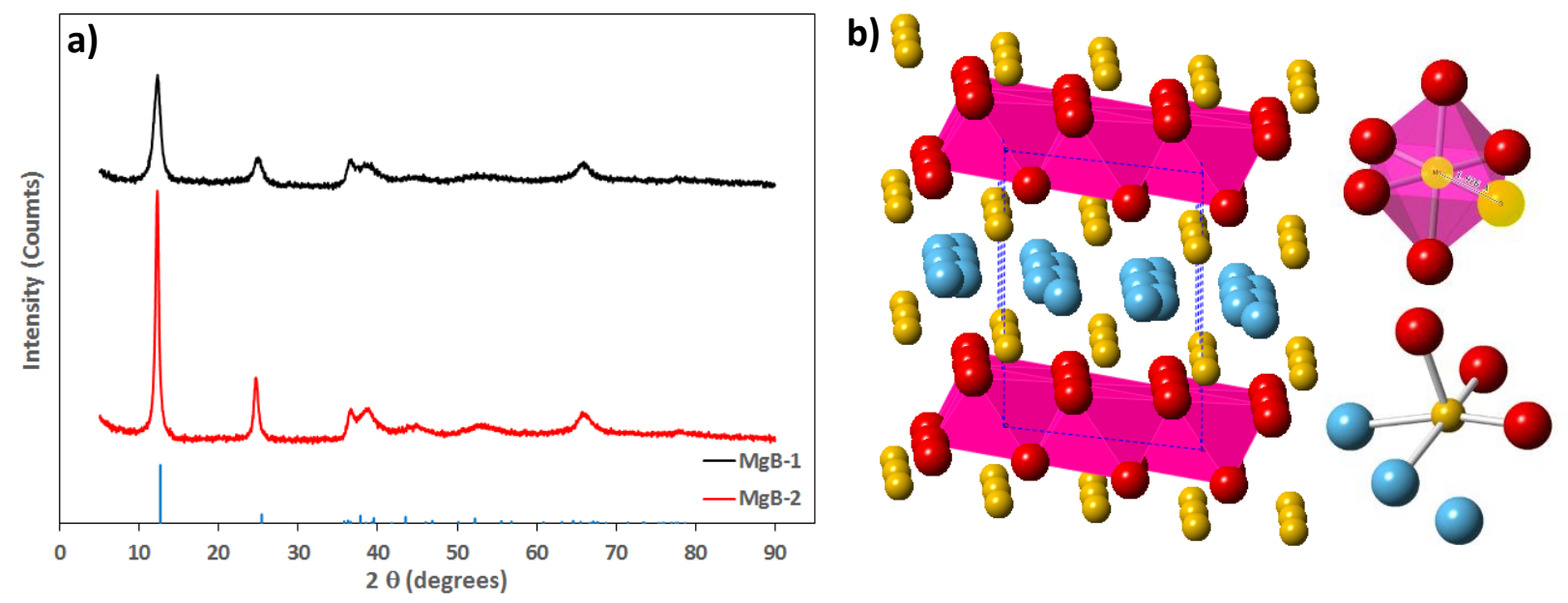

Figure 1. a) X-ray powder diffraction patterns of as-synthesized Mg-birnessite samples. b) Crystal structure of $\mathrm{Mg}$-birnessite along b-axis. Pink octahedra with red balls are edge-shared $\mathrm{MnO}_{6}$ units; yellow balls are $\mathrm{Mg}^{2+}$; blue balls are water molecules. The coordination environments of $\mathrm{Mn}$ and $\mathrm{Mg}$ are also shown. 


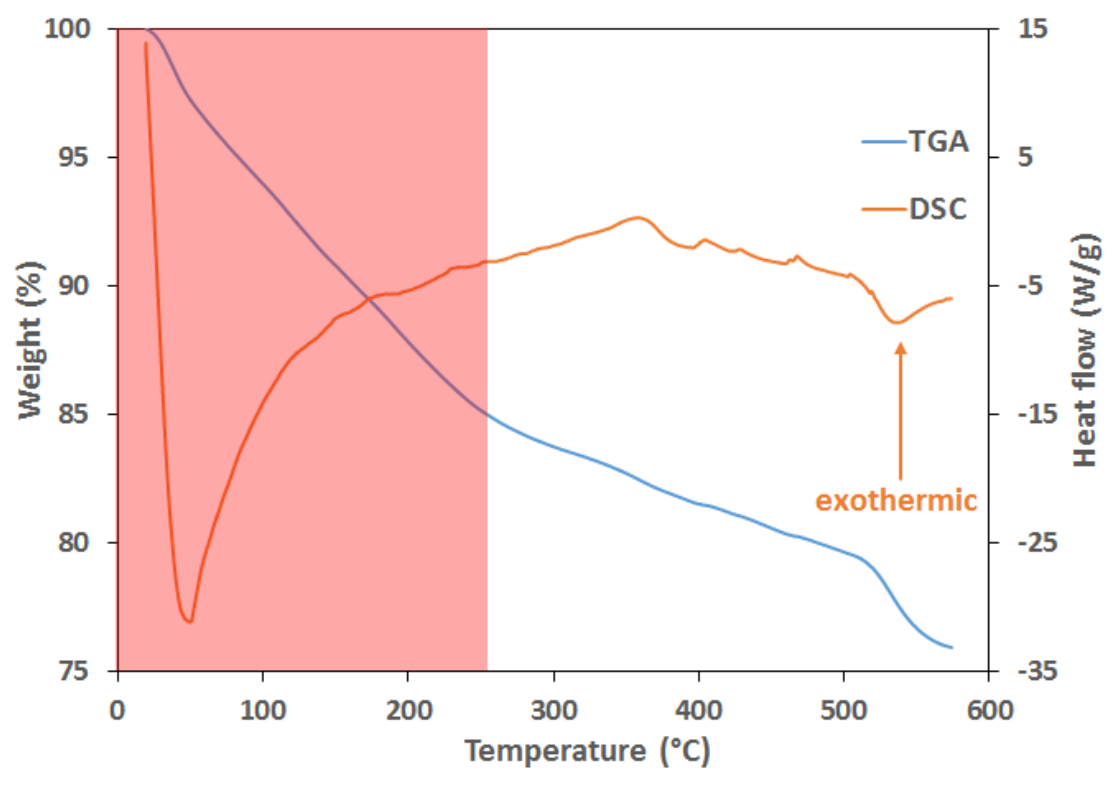

Figure 2. TGA/DSC curve of MgB-1. The pink shaded region indicates the water loss range. 

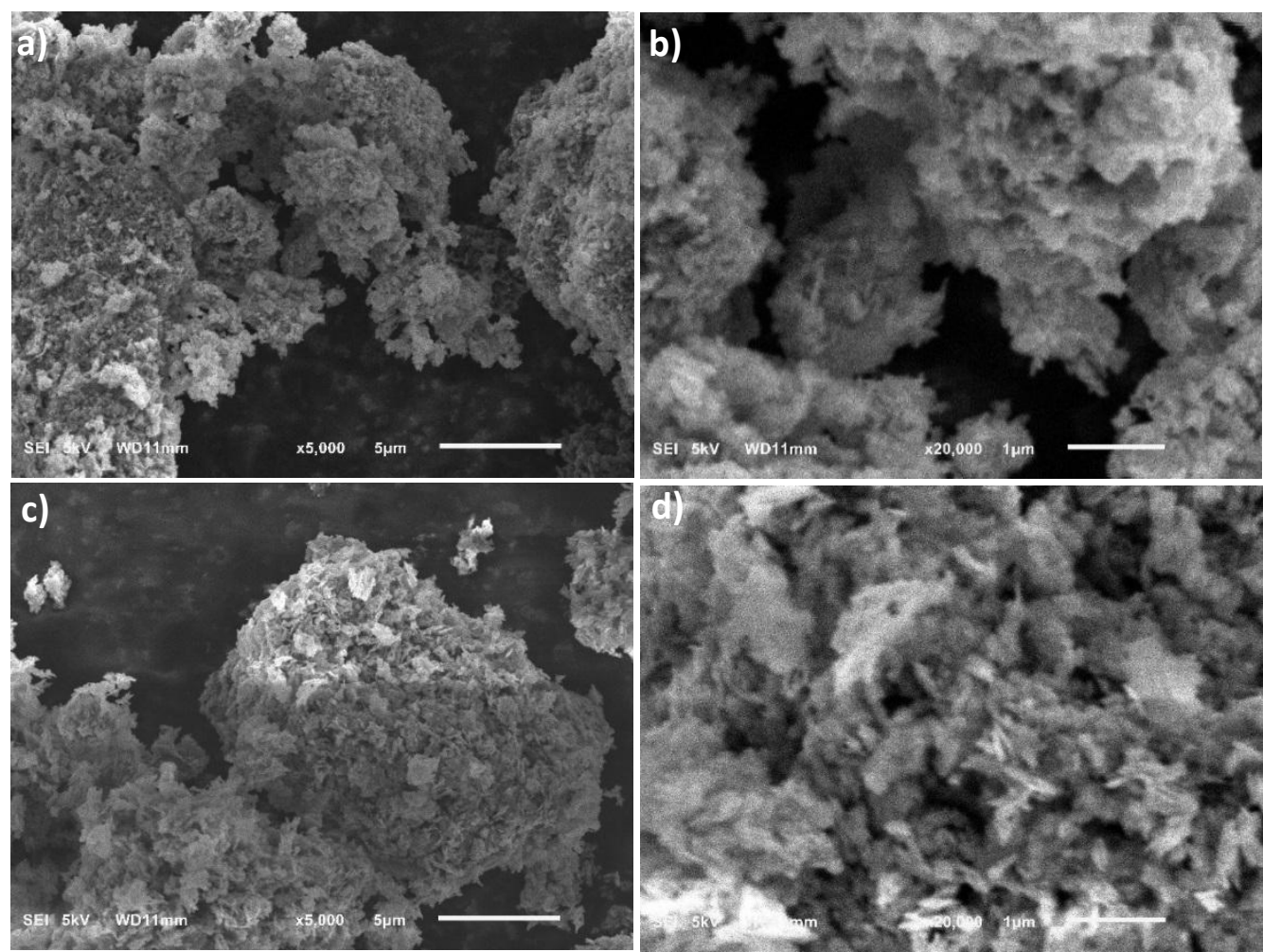

Figure 3. Scanning electron micrographs (SEM) of MgB-1 at a) 5,000X and b) 20,000X, MgB-2 at c) $5,000 \mathrm{X}$ and d) 20,000X. 

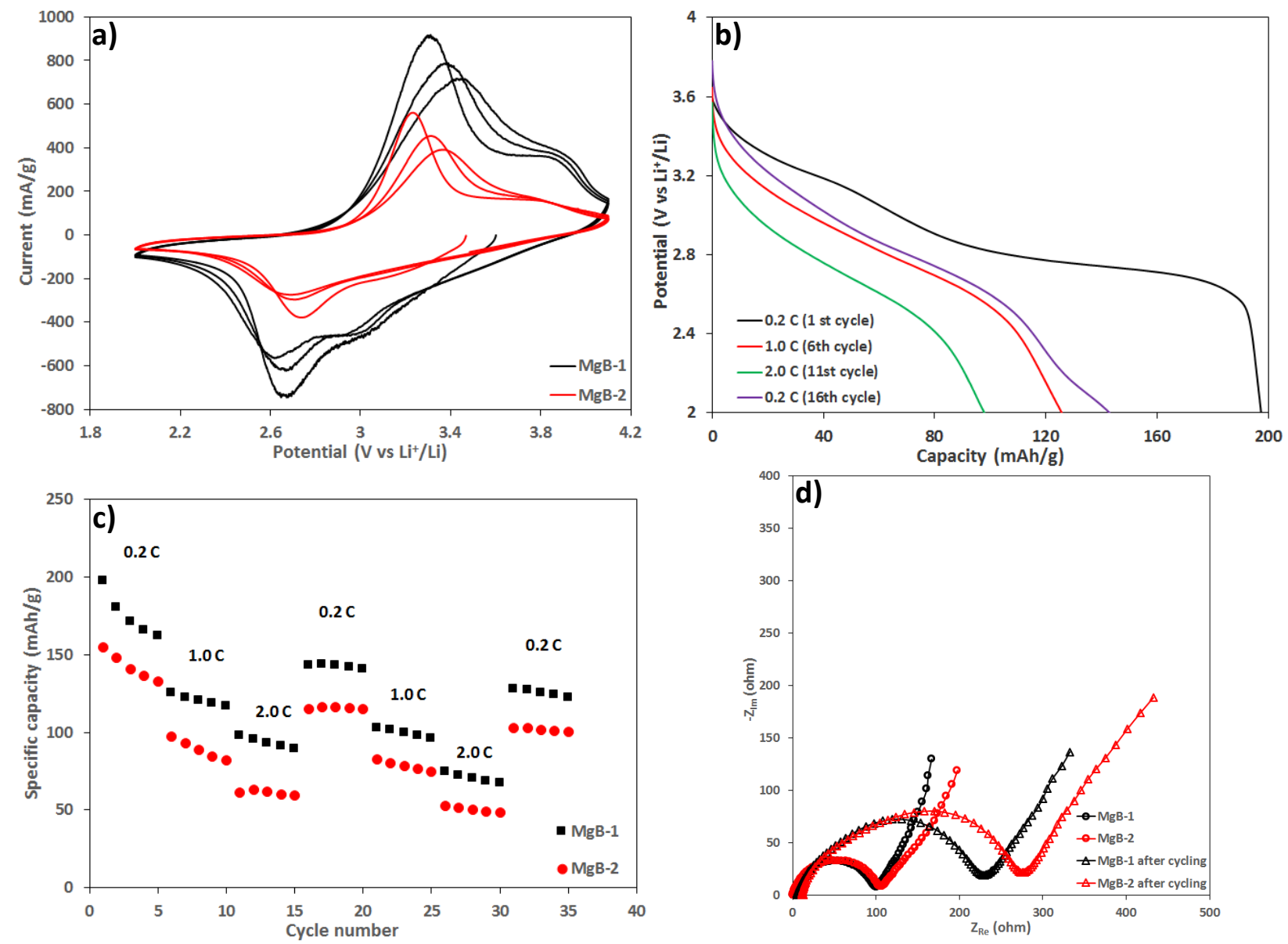

Figure 4. a) Cyclic voltammetry test of MgB-1 $(9 \mathrm{~nm})$ and MgB-2 $(23 \mathrm{~nm})$ in $1 \mathrm{M} \mathrm{LiPF}_{6}$ in EC/DMC (30/70) at $0.5 \mathrm{mV} / \mathrm{s}$ scan rate. b) Discharge curve at different rate, using MgB-1 as example. c) Discharge capacity of Mg-birnessite samples. d) AC impedance spectroscopy results of MgB-1 and MgB-2 before and after galvanostatic cycling test. 

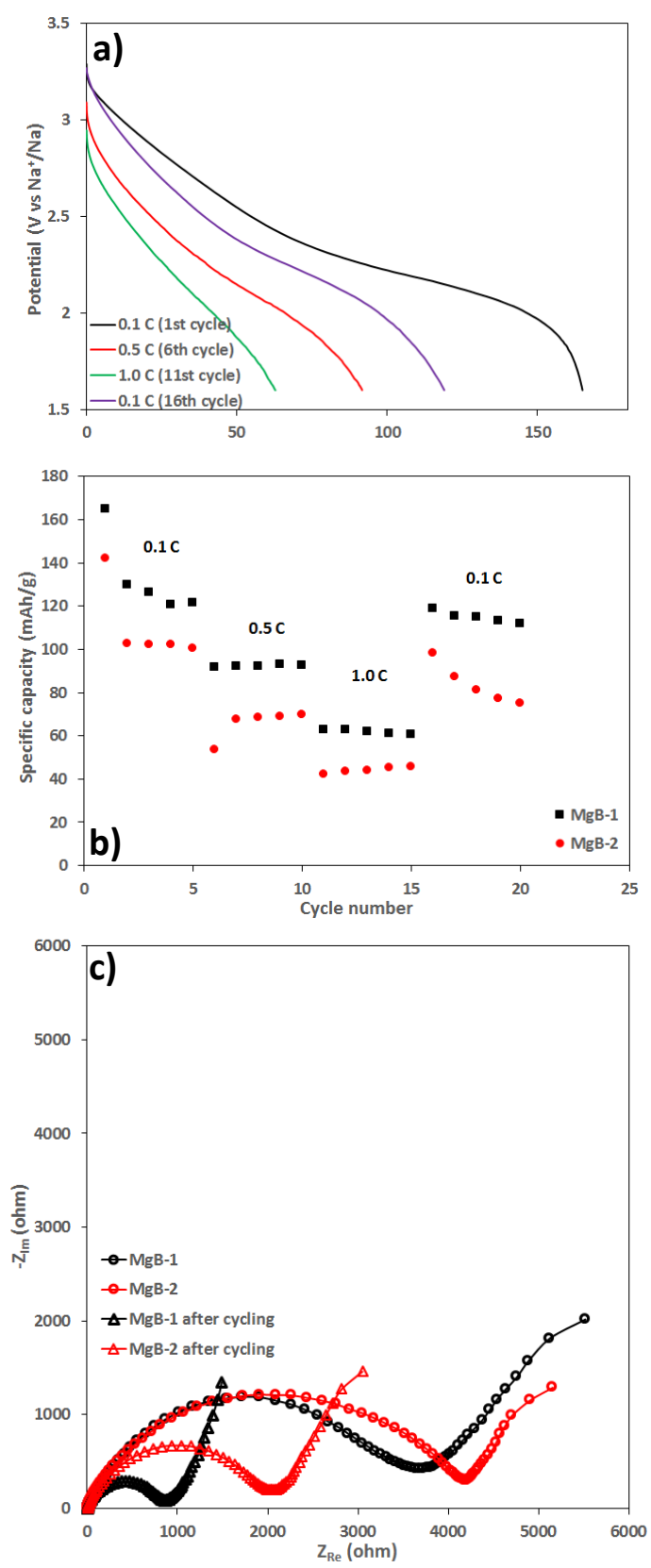

Figure 5. Comparison of galvanostatic cycling results of MgB-1 (9 nm) and MgB-2 $(23 \mathrm{~nm})$ in $1 \mathrm{M}$ $\mathrm{NaPF}_{6}$ in EC/DEC (50/50): a) discharge curves of MgB-1 at different rate; b) Discharge capacity of each cycle. 

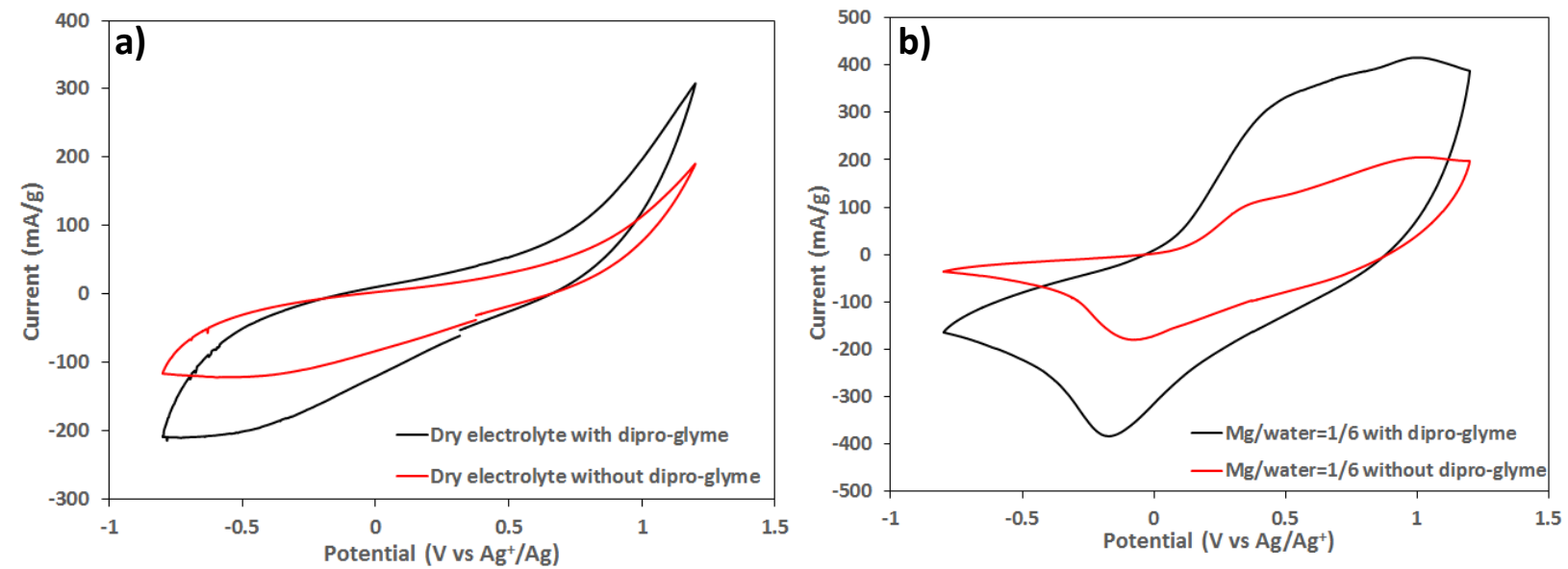

Figure 6. a) Comparison of $2^{\text {nd }}$ cycle in electrolyte in anhydrous $0.4 \mathrm{M} \mathrm{Mg}(\mathrm{TFSI})_{2}$ / acetonitrile with or without dipro-glyme. b) Comparison of $2^{\text {nd }}$ cycle in electrolyte in acetonitrile with or without diproglyme with $\mathrm{Mg}^{2+} /$ water $=1 / 6$ molar ratio. 

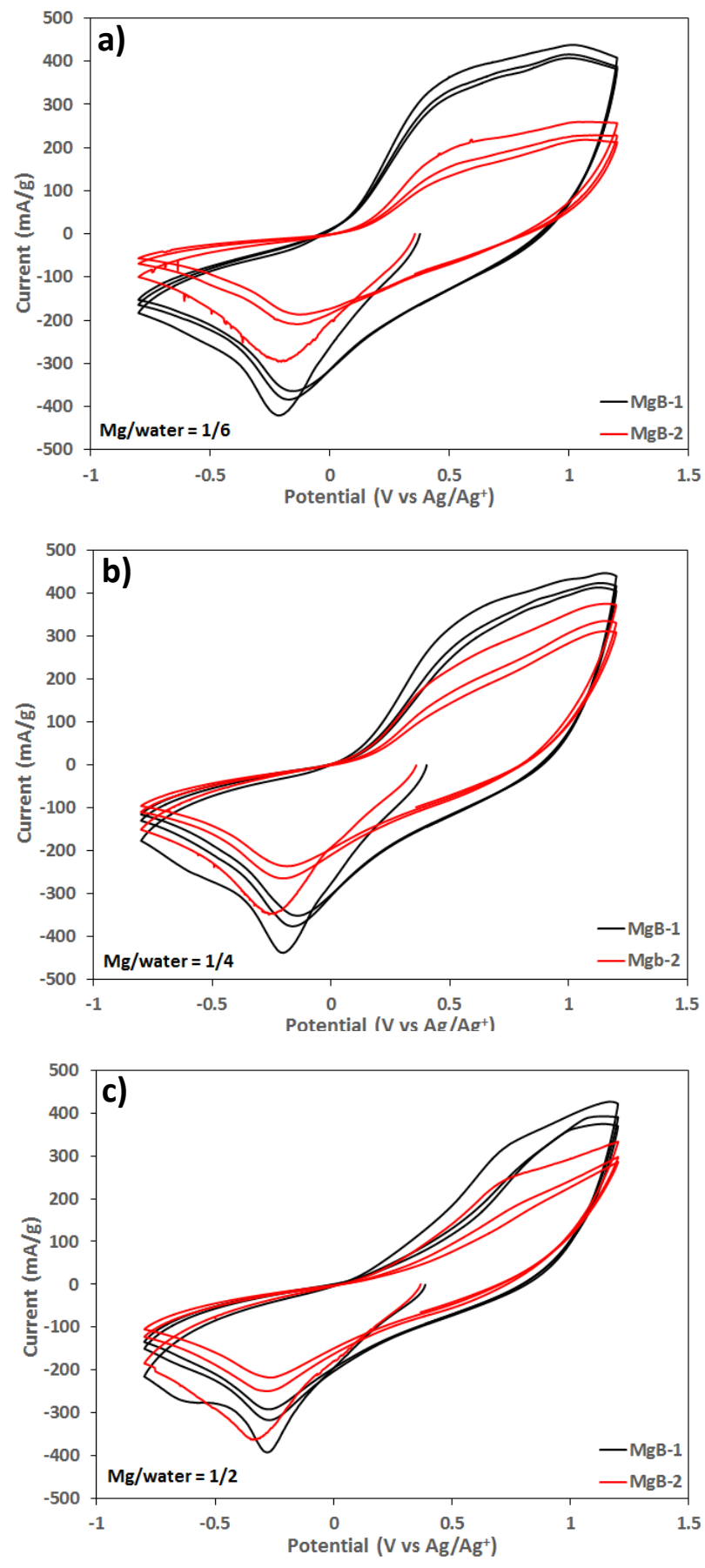

Figure 7. Comparison of cyclic voltammetry results of MgB-1 $(9 \mathrm{~nm})$ and MgB-2 $(23 \mathrm{~nm})$ in $0.4 \mathrm{M}$ $\mathrm{Mg}(\mathrm{TFSI})_{2} /$ acetonitrile and $0.5 \mathrm{M}$ dipro-glyme with different water concentration and scan rate was 0.5 $\mathrm{mV} / \mathrm{s}$. 

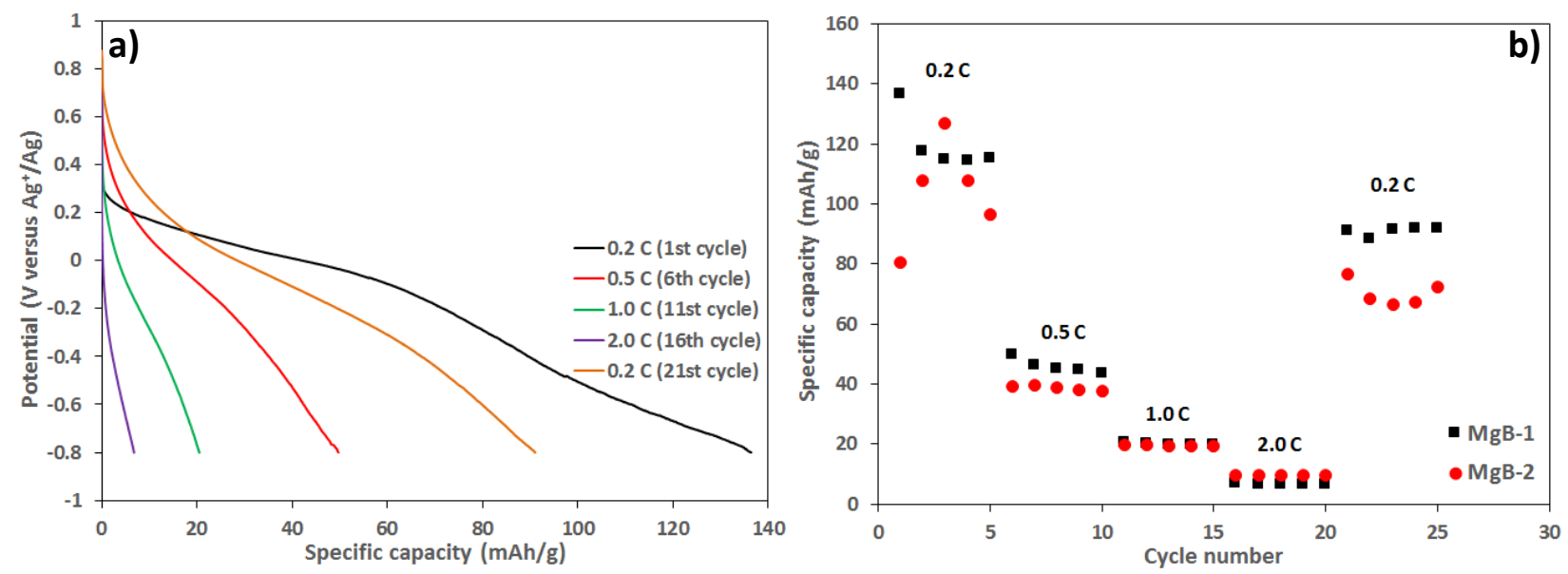

Figure 8. Galvanostatic cycling results of MgB-1 $(9 \mathrm{~nm})$ and MgB-2 (23 nm) in $0.4 \mathrm{M} \mathrm{Mg}(\mathrm{TFSI})_{2} /$ acetonitrile and $0.5 \mathrm{M}$ dipro-glyme with $\mathrm{Mg}^{2+} /$ water=1/6: a) discharge curve at different rate, using MgB1 as example; b) Discharge capacity of each cycle. 

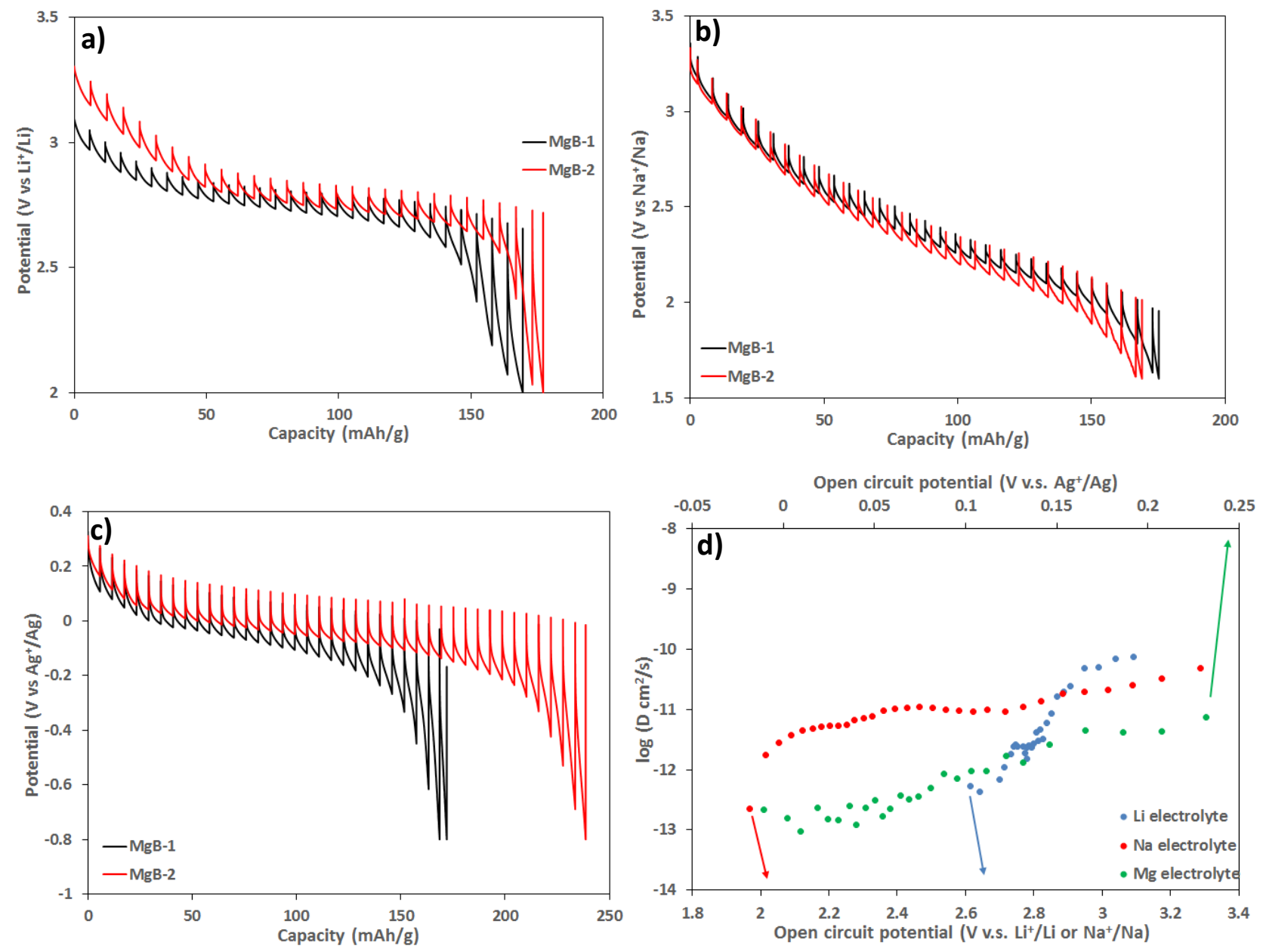

Figure 9. GITT results of MgB-1 and MgB-2 in a) $\mathrm{Li}^{+}$electrolyte, b) $\mathrm{Na}^{+}$electrolyte, c) $\mathrm{Mg}^{2+}$ electrolyte.

d) Cation diffusion coefficients in MgB-1 in different electrolyte systems, calculated from GITT test. 